\title{
International travel and acquisition of multidrug- resistant Enterobacteriaceae: a systematic review
}

\author{
RJ Hassing ${ }^{123}$, J Alsma ${ }^{34}$, MS Arcilla ${ }^{5}$, PJ van Genderen ${ }^{6}$, BH Stricker ${ }^{17}$, A Verbon 45 \\ 1. Department of Epidemiology, Erasmus University Medical Center, Rotterdam, the Netherlands \\ 2. Department of Internal Medicine, Rijnstate Hospital and Travel Clinic Oost, Arnhem, the Netherlands \\ 3. These authors contributed equally to this article \\ 4. Department of Internal Medicine, Erasmus University Medical Center, Rotterdam, the Netherlands \\ 5. Medical Microbiology and Infectious Diseases, Erasmus University Medical Center, Rotterdam, the Netherlands \\ 6. Institute for Tropical Diseases, Havenziekenhuis, Rotterdam, the Netherlands \\ 7. Inspectorate of Health Care, Utrecht, the Netherlands
}

Correspondence: Robert-Jan Hassing (RHassing@rijnstate.nl)

Citation style for this article:

Hassing RJ, Alsma J, Arcilla M, van Genderen P, Stricker B, Verbon A. International travel and acquisition of multidrug-resistant Enterobacteriaceae: a systematic review. Euro Surveill. 2015;20(47):pii=30074. DOI: http://dx.doi.org/10.2807/1560-7917.ES.2015.20.47.30074

Article submitted on 10 March 2015 / accepted on 23 September 2015 / published on 26 November 2015

International travel is considered to be an important risk factor for acquisition of multidrug-resistant Enterobacteriaceae (MRE). The aim of this systematic review was to determine the effect of international travel on the risk of post-travel faecal carriage of MRE. Secondary outcomes were risk factors for acquisition of MRE. A systematic search for relevant literature in seven international databases was conducted according to Preferred Reporting Items for Systematic Reviews and Meta-Analyses (PRISMA) guidelines. Articles needed to report on (i) foreign travel, (ii) screening of asymptomatic participants, (iii) antimicrobial susceptibility data and (iv) faecal Enterobacteriaceae carriage. Two researchers independently screened the abstracts, assessed the full article texts for eligibility and selected or rejected them for inclusion in the systematic review. In case of disagreement, a third researcher decided on inclusion. Eleven studies were identified. In all studies, a high prevalence (>20\%) of carriage of MRE after international travel was found. The highest prevalence was observed in travellers returning from southern Asia. Foreign travel was associated with an increased risk of carriage of MRE. Further research is needed to assess if this leads to an increase in the number of infections with MRE. Systematic review registration number: PROSPERO CRD42015024973.

\section{Introduction}

\section{Rationale}

Worldwide, the number of international travellers has grown from 25 million in 1950 to 1,087 million in 2013 [1]. According to the World Tourism Organization, this number is expected to increase by an average of 3.3\% a year [1]. Of the international travellers visiting developing countries, $22-64 \%$ have self-reported health problems and about $8 \%$ require medical care during or after travel $[2,3]$. Healthy travellers may be exposed to a broad range of microorganisms while travelling, including drug-resistant Enterobacteriaceae, which may subsequently be introduced into their home country $[4,5]$.

Enterobacteriaceae are Gram-negative bacteria that are part of the human body's normal commensal flora, called microbiota. Enterobacteriaceae, such as Escherichia coli and Klebsiella species, are capable of causing both healthcare-associated and community-acquired infections [6]. Multidrug-resistant Enterobacteriaceae (MRE), including extended-spectrum beta-lactamase (ESBL)producing Enterobacteriaceae (ESBL-E) and plasmidmediated Amp C-producing Enterobacteriaceae (pAmp C-E) are emerging worldwide [7]. Cases of carbapenemase-producing Enterobacteriaceae (CPE) are also reported more frequently [8].

Since 2003 , community carriage rates of MRE have increased dramatically in various regions, such as South-East Asia, the Western Pacific and the Eastern Mediterranean [7]. During visits to such areas, travellers might acquire MRE and become asymptomatic carriers of MRE. In their home country, they may cause spread in the community and contribute to worldwide emerging antimicrobial resistance $[6,9,10]$. Acquired MRE in the digestive tract are considered apathogenic, however carriage of such Enterobacteriaceae have resulted in clinically relevant infections [8]. International travel has been reported as a risk factor for urinary tract infections caused by ESBL-E $[11,12]$. The question arises if these observations warrant clinicians being aware of MRE in recently returned otherwise healthy, international travellers who seek medical attention even for unrelated conditions. 


\section{FIGURE}

Flowchart for literature search on the acquisition of multidrug-resistant Enterobacteriaceae in international travel $(\mathrm{n}=4,989)$

Articles identified in Embase, MEDLINE, Web of Science, Scopus, The Cochrane Library, PubMed and Google Scholar $(n=5,189)$

Articles identified by searching references in published articles $(n=0)$

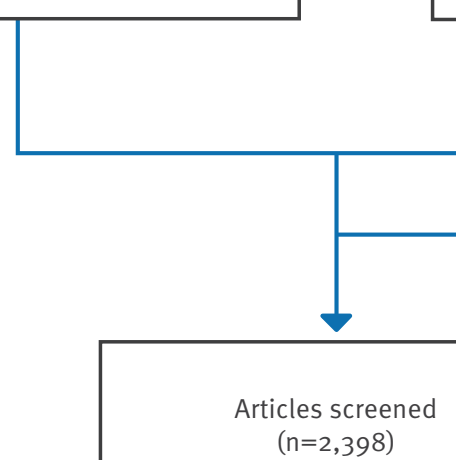

Duplicates removed $(n=2,791)$

$$
(n=2,398)
$$

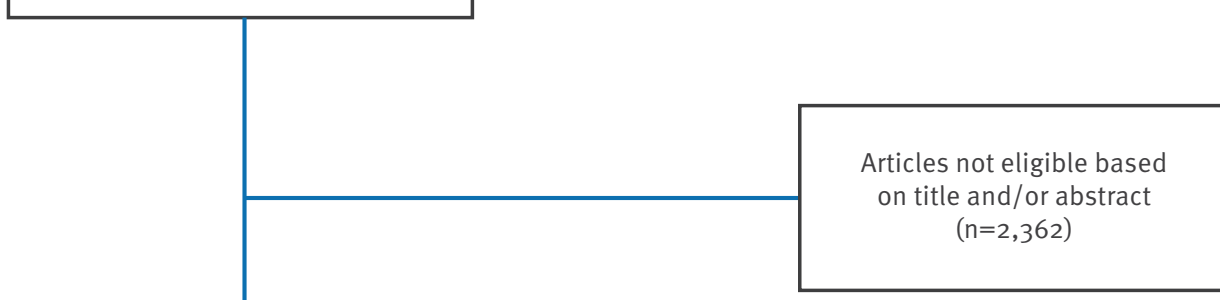

Articles retrieved for further evaluation $(n=36)$

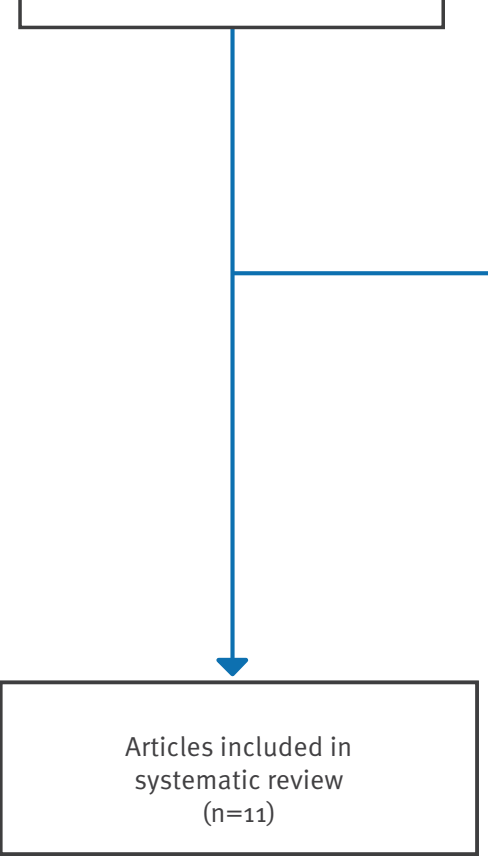

Studies excluded for the following reasons $(n=25)$ :

Letter to the editor $(n=2)$

Review $(n=4)$

Study design $(\mathrm{n}=1)$

Oral or poster presentation (3)

No ESBL-Enterobacteriaceae $(\mathrm{n}=6)$

Symptomatic patients $(n=7)$

No travel $(n=1)$

Results of a follow-up study $(n=1)$ 
Search strategy for systematic review of the acquisition of multidrug-resistant Enterobacteriaceae in international travel

\begin{abstract}
Embase.com ('Gram negative bacterium'/exp OR 'Gram negative infection'/de OR Enterobacteriaceae/de OR Escherichia/exp OR Klebsiella/exp OR Salmonella/exp OR Shigella/exp OR Yersinia/exp OR 'Enterobacteriaceae infection'/exp OR ('Gram negative’ OR Enterobacteri* OR (Enter* NEXT/1 bacteria*) OR Enterobacter* OR Escherichia* OR 'e coli' OR Klebsiella* OR Salmonell* OR Shigell* OR Yersinia*):ab,ti) AND (travel/de OR 'traveller diarrhoea'/de OR aviation/exp OR (travel* OR touris* OR turista OR aviation OR 'air transport' OR airport*):ab,ti) AND ('antibiotic resistance'/exp OR 'multidrug resistance'/de OR 'drug resistance'/de OR 'antibiotic sensitivity'/de OR 'bacterial colonization'/exp OR 'bacterium carrier'/de OR (resistan* OR coloni* OR ((antibiotic* OR antimicrob*) NEAR/3 sensitivit*) OR susceptib* OR carriage* OR carrier*):ab,ti) NOT ([animals]/lim NOT [humans]/lim)
\end{abstract}

MEDLINE (OvidSP) (exp “Gram-Negative Bacteria"/ OR exp "Gram-Negative Bacterial Infections"/ OR Enterobacteriaceae/ OR exp Escherichia/ OR exp Klebsiella/ OR exp Salmonella/ OR exp Shigella/ OR exp Yersinia/ OR exp "Enterobacteriaceae infections”/ OR (“Gram negative" OR Enterobacteri* OR (Enter* ADJ bacteria*) OR Enterobacter* OR Escherichia* OR "e coli” OR Klebsiella* OR Salmonell* OR Shigell* OR Yersinia*).ab,ti.) AND (travel/ OR “Travel Medicine”/ OR exp aviation/ OR (travel* OR touris* OR turista OR aviation OR “air transport" OR airport*).ab,ti.) AND (exp "Drug Resistance, Microbial”/ OR exp "Drug Resistance, Multiple"/ OR “drug resistance"/ OR "bacterium carrier"/ OR (resistan* OR coloni* OR ((antibiotic* OR antimicrob*) ADJ3 sensitivit*) OR susceptib* OR carriage* OR carrier*).ab,ti.) NOT (exp animals/ NOT humans/)

Cochrane Library (('Gram negative’ OR Enterobacteri* OR (Enter* NEXT/1 bacteria*) OR Enterobacter* OR Escherichia* OR 'e coli’ OR Klebsiella* OR Salmonell* OR Shigell* OR Yersinia*):ab,ti) AND ((travel* OR touris* OR turista OR aviation OR 'air transport' OR airport*):ab,ti) AND ((resistan* OR coloni* OR ((antibiotic* OR antimicrob*) NEAR/3 sensitivit*) OR susceptib* OR carriage* OR carrier*):ab,ti)

Web of Science TS $=((($ “Gram negative” OR Enterobacteri* OR (Enter* NEAR/1 bacteria*) OR Enterobacter* OR Escherichia* OR "e coli” OR Klebsiella* OR Salmonell* OR Shigell* OR Yersinia*)) AND ((travel* OR touris* OR turista OR aviation OR “air transport” OR airport*)) AND ((resistan* OR coloni* OR ((antibiotic* OR antimicrob*) NEAR/3 sensitivit*) OR susceptib* OR carriage* OR carrier*)))

Scopus TITLE-ABS-KEY((c“Gram negative” OR Enterobacteri* OR (Enter* W/1 bacteria*) OR Enterobacter* OR Escherichia* OR "e coli” OR Klebsiella* OR Salmonell* OR Shigell* OR Yersinia*)) AND ((travel* OR touris* OR turista OR aviation OR “air transport” OR airport*)) AND ((resistan* OR coloni* OR ((antibiotic* OR antimicrob*) W/3 sensitivit*) OR susceptib* OR carriage* OR carrier*)))

PubMed ((Gram negative[tiab] OR Enterobacteri*[tiab] OR Entero bacteria*[tiab] OR Enteric bacteria*[tiab] OR Enterobacter*[tiab] OR Escherichia*[tiab] OR e coli[tiab] OR Klebsiella*[tiab] OR Salmonell*[tiab] OR Shigell*[tiab] OR Yersinia*[tiab])) AND ((travel*[tiab] OR touris*[tiab] OR turista[tiab] OR aviation[tiab] OR air transport*[tiab] OR airport*[tiab])) AND ((resistan*[tiab] OR coloni*[tiab] OR ((antibiotic*[tiab] OR antimicrob*[tiab]) AND sensitivit*[tiab]) OR susceptib*[tiab] OR carriage*[tiab] OR carrier*[tiab])) AND publisher[sb]

Google Scholar "Gram negative"|Enterobacteriaceae|Escherichia|Klebsiella|Salmonella|Shigella|Yersinia travel|traveller|tourist|tourism resistance|resistant|colonization|colonisation|susceptibility|carriage|carrier

\section{Objectives}

The aim of this systematic review was to determine the effect of international travel on the risk of acquisition of faecal carriage of MRE. A secondary objective was to determine risk factors for acquisition of drug resistance.

\section{Methods}

\section{Protocol and registration}

A specific protocol was designed and used to conduct the study. The study is registered in the international prospective register of systematic reviews (PROSPERO) under registration number CRD42015024973.

\section{Search strategy and selection criteria}

The systematic review was conducted according to Preferred Reporting Items for Systematic Reviews and Meta-Analyses (PRISMA) guidelines [13]. The following databases were searched, attempting to identify all relevant studies: Embase, MEDLINE, Web of Science, Scopus, Cochrane Library, PubMed and Google Scholar. The latest search was conducted on 17 August 2015.

The topic search terms used for searching the databases were 'Gram negative bacteria', 'Gram negative bacterial infections', 'Enterobacteriaceae', 'Escherichia', 'Klebsiella', 'Campylobacter', 'Salmonella', 'Shigella', 'Yersinia', 'travel', 'traveller', 'tourist', 'tourism', 'turista', 'aviation', 'air transport', 'airport', 'colonisation', 'carriage', 'carrier', 'susceptibility' and '(multiple) drug resistance’.

The queries differed per database searched and were developed with help of a biomedical information specialist (Box). Articles written in English, German, French and Dutch were included.

For inclusion the article needed to fulfil the following criteria [1]: It needed to be related to foreign travel [2], report on screening in asymptomatic participants [3], present antimicrobial susceptibility data and [4] report on faecal Enterobacteriaceae carriage. We used the following exclusion criteria: case reports, reviews, metaanalyses, veterinary medicine, in vitro studies and studies regarding symptomatic patients. The reference lists of reviews were screened to identify studies possibly missed by the search.

Two researchers (R.H. and J.A.) independently performed the screening of the abstracts. Any discordant result was discussed in consensus meetings. After 
screening the abstracts, the full text of the articles was assessed for eligibility by the same two researchers and selected or rejected for inclusion in the systematic review. In case of disagreement a third researcher (A.V.) decided on inclusion.

\section{Data collection process}

The following data (if available) were extracted from each article: year of publication, country of the study, study period, study design, microorganism studied, study population, study size, age, sex, sample time before and after travel, duration of travel, travelling in pairs or groups, symptoms during travel, countries visited, MRE prevalence before travel, MRE prevalence after travel, MRE resistance acquired during travel, resistance to other antibiotic drugs of acquired MRE, risk factors for acquisition (among which travel to predefined United Nations geographical regions: southern Asia, Asia except southern Asia, Africa, South and Central America, North America, Europe and Oceania [14]), method of MRE susceptibility determination, phenotypic approaches, genotypic characterisation of post-travel MRE isolates, molecular typing of posttravel MRE isolates, duration of MRE colonisation and MRE transmission to household contacts. To obtain missing data, authors of the articles were contacted.

\section{Quality assessment}

We assessed the methodological quality and the risk of bias in individual studies that may affect the cumulative evidence, using tools for assessing quality and susceptibility to bias in observational studies as recommended in the Strengthening the Reporting of Observational Studies in Epidemiology (STROBE) Statement $[15,16]$.

\section{Data synthesis and analysis}

As a result of the design of the studies (cohort studies) and the heterogeneity in patient populations (e.g. travellers, healthcare workers and healthcare students), a formal meta-analysis was not possible. Therefore, the study results were summarised to describe the main outcomes of interest. The principle summary measure was percentage of MRE acquisition during travel, defined as ESBL-E or pAmp C-E. Furthermore, risk factors for acquisition of drug resistance were assessed. If possible, percentages not presented in the articles were calculated from the available data.

\section{Results}

\section{Study selection}

A total of 2,398 studies were identified through database searching after duplicates had been removed (Figure). After screening of titles and summaries, 36 articles were selected for full-text assessment. Eleven articles were included in the qualitative synthesis of the systematic review (see Figure for reasons for exclusion) [17-27].

\section{Study characteristics}

Eleven prospective cohort studies, conducted in northern and western Europe, Australia and the United States (US) were included [17-27]. The characteristics of these studies are shown in Table 1 . Nine studies investigated travellers visiting a travel or vaccination clinic, one study hospital staff and contacts, and one study healthcare students working or studying abroad. The number of study participants ranged from 28 to 574 . The median age of travellers in the individual studies varied between 25 and 66 years, with the youngest group being healthcare students. In all studies, the majority of travellers were female (range: $55-78 \%$ ). The proportion of participants who were lost to follow up varied from $3.8 \%(4 / 106)$ [18] to $30 \%(12 / 40)$ [21]. The mean duration of travel was similar in all studies (1421 days). In the study by Angelin et al. on healthcare students, median length of stay was 45 days (range: 13-365 days) [22]. In four studies, follow-up samples of MRE carriers were collected at six months after returning from travel, and in one of these studies, samples were collected monthly in the first three months with further follow-up until 12 months after return [25]. Ten studies used a phenotypic method for susceptibility testing, with genotypic confirmation of ESBL positivity by PCR [17-22,24-27]. One study used a PCR-based approach [23]. In one study, only isolated E. coli were included, whereas the other studies included all isolated Enterobacteriaceae, which mainly consisted of $E$. coli [17-27].

\section{Acquisition of multidrug-resistant \\ Enterobacteriaceae}

Faecal carriage of MRE varied from 1 to $12 \%$ before travel and acquisition of MRE from $21 \%$ to $51 \%$ (Table $2[17-21,23-27]$.

In the study by Kuenzli et al. on travellers to the Indian subcontinent only, a much higher MRE acquisition rate of $69 \%$ was demonstrated [26]. The risk of acquisition of MRE varied with the geographical region (Table 3) [17-21,23-27]. Travel to southern Asia posed the highest risk (range: $29-88 \%$ ), followed by other Asian countries (18-67\%) and Northern Africa (range: 31-57\%). Acquisition of MRE after travelling to sub-Saharan Africa (range: $0-49 \%$ ) or South and Central America (range: 0-33\%) was less frequent, and three studies did not observe any acquisition of MRE after travel to South or Central America (Table 3). Acquisition of MRE after travel to North America, Europe and Oceania was rare. Results of the genotypic characterisation of MRE isolated after travel are presented in Table 2, the majority of the genes belonged to the CTX-M type.

\section{Risk factors for acquisition of multidrug- resistant Enterobacteriaceae}

Besides travel destinations, other risk factors for acquiring MRE were age, use of antibiotics during travel (beta-lactam use) and gastroenteritis or other gastrointestinal symptoms (Table 2). The study of Kantele et al., designed to study these risk factors as primary 


\begin{tabular}{|c|c|c|c|c|c|c|c|c|c|c|c|c|}
\hline 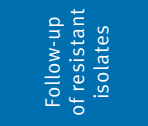 & 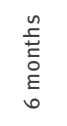 & $\begin{array}{l}\text { n } \\
\underline{E} \\
\bar{E} \\
\underline{E} \\
0\end{array}$ & $\begin{array}{l}\stackrel{0}{5} \\
\stackrel{5}{2}\end{array}$ & 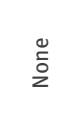 & 总 & 蒿 & $\begin{array}{l}\stackrel{0}{\circ} \\
\stackrel{0}{2}\end{array}$ & 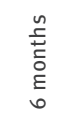 & 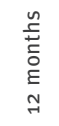 & $\begin{array}{l}\stackrel{0}{0} \\
\stackrel{0}{2}\end{array}$ & 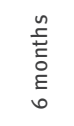 & \\
\hline 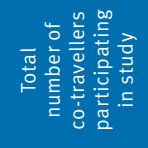 & $\tilde{\sim}$ & 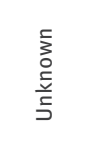 & 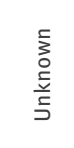 & $\infty$ & 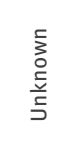 & 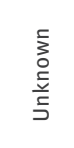 & 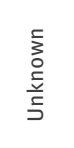 & $\stackrel{0}{\check{0}}$ & $\begin{array}{l}\stackrel{0}{5} \\
\stackrel{5}{2}\end{array}$ & 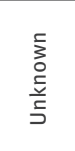 & N & \\
\hline 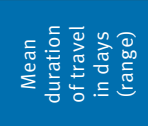 & 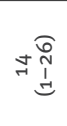 & 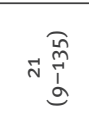 & 章 & a商 & 袋 & 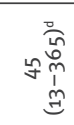 & 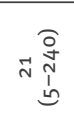 & त高 & 욜 & $\stackrel{\infty}{\sim} \underset{\tilde{w}}{\stackrel{\hat{n}}{\omega}}$ & $\vec{\sim} \underset{\substack{\infty \\
\tilde{m}}}{\stackrel{\omega}{n}}$ & \\
\hline 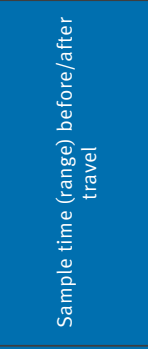 & 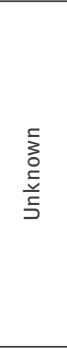 & 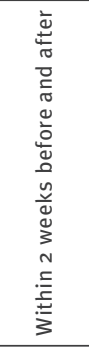 & 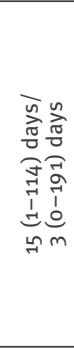 & 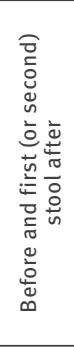 & 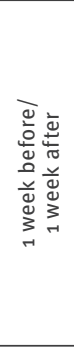 & 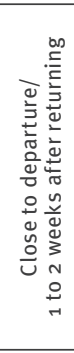 & 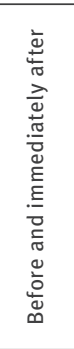 & 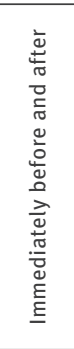 & 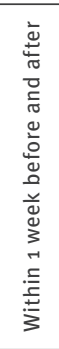 & 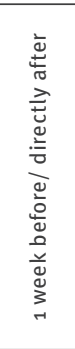 & 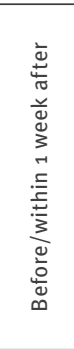 & \\
\hline 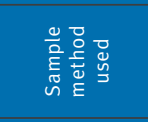 & $\begin{array}{l}\bar{\circ} \\
\stackrel{\circ}{\omega}\end{array}$ & 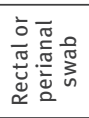 & 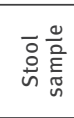 & 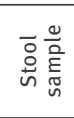 & 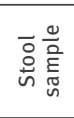 & 总产 & 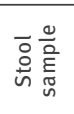 & 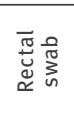 & 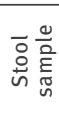 & 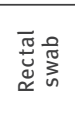 & 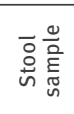 & \\
\hline 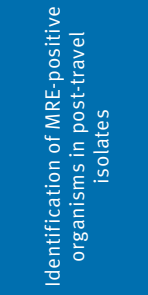 & 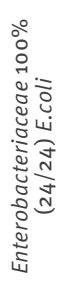 & 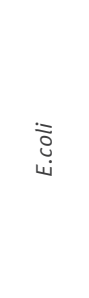 & 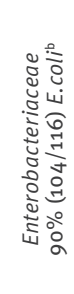 & 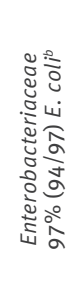 & 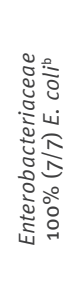 & 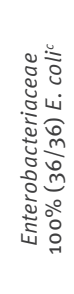 & 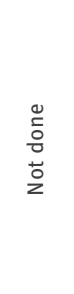 & 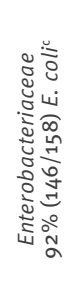 & 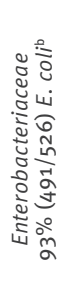 & 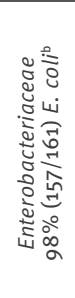 & 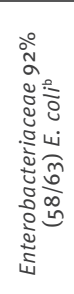 & \\
\hline 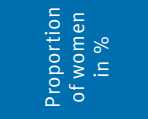 & in & $\tilde{\sigma}$ & in & $\overrightarrow{0}$ & $\stackrel{\infty}{\infty}$ & $\stackrel{\infty}{\wedge}$ & $\stackrel{\infty}{n}$ & $\tilde{\varphi}$ & $\vec{b}$ & in & in & \\
\hline 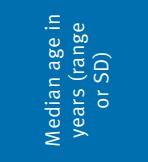 & 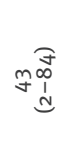 & 隹 & 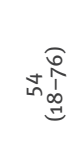 & 䬶 & 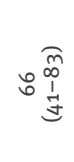 & 올 & 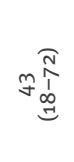 & 离 & m. & $F \hat{\sigma}$ & 隽旁 & 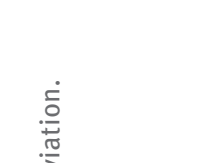 \\
\hline 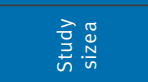 & $\stackrel{\sim}{\circ}$ & $\stackrel{N}{\sim}$ & $\overrightarrow{\tilde{N}}$ & 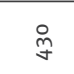 & $\stackrel{\infty}{N}$ & o & $\tilde{N}$ & $\stackrel{\circ}{i}$ & in & $\stackrel{ }{ᄀ}$ & $\stackrel{n}{\sim}$ & \\
\hline 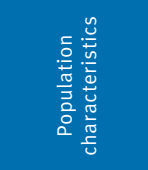 & 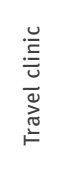 & 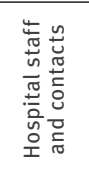 & 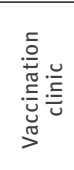 & 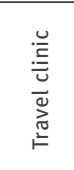 & 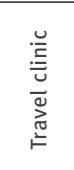 & 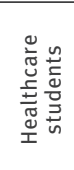 & 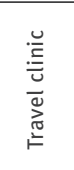 & 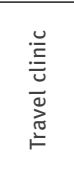 & 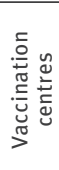 & 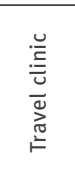 & 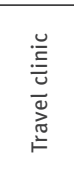 & 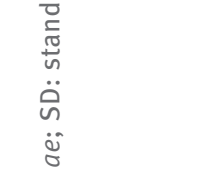 \\
\hline 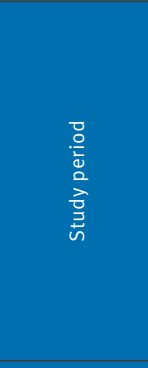 & 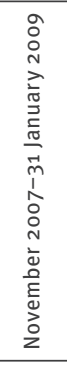 & 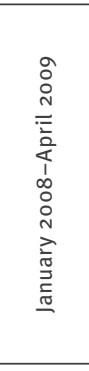 & 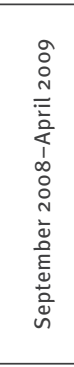 & 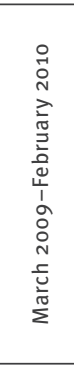 & 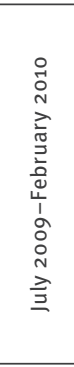 & 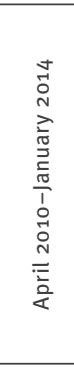 & 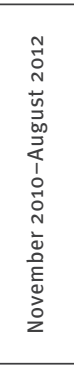 & 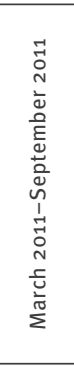 & 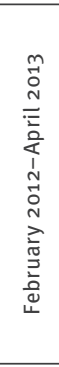 & 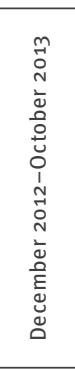 & 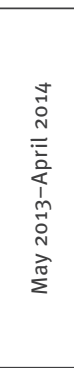 & 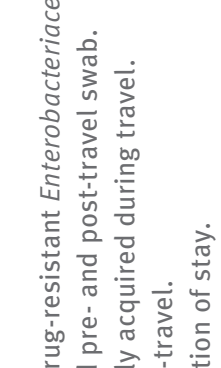 \\
\hline 言 & 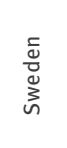 & 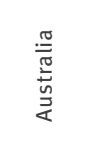 & 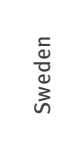 & 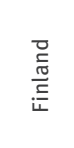 & 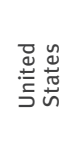 & 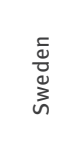 & 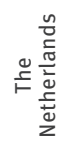 & 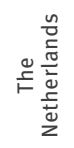 & 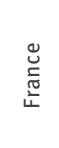 & 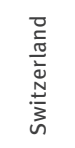 & 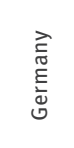 & 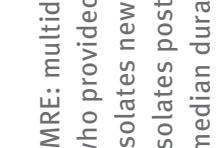 \\
\hline 总 & 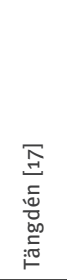 & 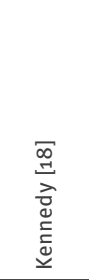 & 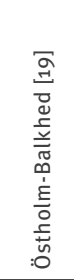 & 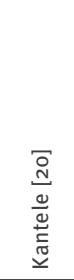 & 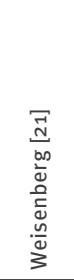 & 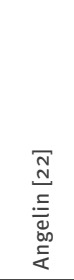 & 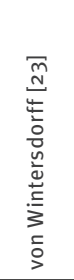 & 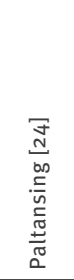 & 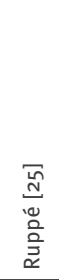 & 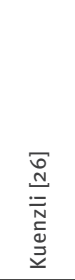 & 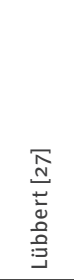 & 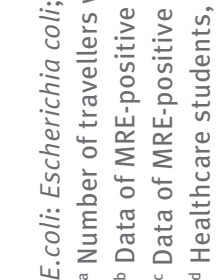 \\
\hline
\end{tabular}


outcome, showed that travel diarrhoea (adjusted odds ratio $(A O R)=31.0 ; 95 \%$ confidence interval $(\mathrm{Cl})$ : 2.7-358.1)) and antibiotic therapy for travel diarrhoea $(A O R=3.0 ; 95 \% \mathrm{Cl}: 1.4-6.7)$ proved to be the most important risk factors for acquiring MRE [20]. In the study of Kuenzli et al. in which only travellers to southern Asia were included, risk factors for MRE acquisition were length of stay, visit to family or friend and consumption of ice cream or pastry (Table 2) [26]. Angelin et al. found a significant association for travel to the South-East Asia region ( $\mathrm{OR}=30$; $95 \% \mathrm{Cl}$ : 6.3-147.2), and antibiotic treatment during travel $(O R=5 ; 95 \%$ $\mathrm{Cl}$ : 1.1-26.2), but found no association with travellers' diarrhoea or patient-related healthcare work [22].

\section{Resistance of multidrug-resistant}

\section{Enterobacteriaceae to other antibiotic drugs}

Resistance of post-travel MRE isolates to various antibiotics was determined in nine studies (Table 4) [1719,21-24,26,27]. In the study by Wintersdorff et al., a PCR-based approach was used, therefore it was not possible to determine which microorganism carried the resistance genes [23]. The resistance data to other antibiotic drugs in the study by Kennedy et al. were not part of the publication, but were provided on request [18]. Antimicrobial resistance was high for ciprofloxacin, varying from $31 \%$ to $57 \%$, and for cotrimoxazole, varying from $49 \%$ to $86 \%[17-19,21-24,26,27]$. Aminoglycoside resistance was high for gentamicin (range: $17-50 \%$ ) and tobramycin (range: $18-59 \%$ ) and low for amikacin (range: 2-5\%) [17-19,21-24,26,27]. Carbapenemase-producing Enterobacteriaceae were observed in four travellers who had all visited India (in the study by Ruppé et al., two OXA-181 and one New Delhi metallo-beta-lactamase 1 (NDM-1), and in the study by Kuenzli et al., one NDM-1 but this strain was not included in the resistance results) $[25,26]$. Resistance to nitrofurantoin, colistin and fosfomycin was only analysed in some of the studies (Table 4) $[18,19,21-23,26]$.

\section{Duration of multidrug-resistant}

Enterobacteriaceae carriage after return, risk factors for a long duration and rate of infection after travel

Five studies analysed MRE carriage six months after travel, and the persistence rate of acquired MRE after six months was $6-24 \%$ of travellers (Table 2) $[17,18,24,25,27]$. Ruppé et al. analysed MRE carriage one, two, three, six and twelve months after travel, showing persistence of carriage of an acquired MRE in $34,19,10,5$ and $2 \%$, respectively [25]. Travellers to Asia showed longer carriage of MRE compared with other travel destinations. Carriage of multidrug-resistant $E$. coli had a lower risk for prolonged carriage than other multidrug-resistant species. No other risk factors were found for prolonged carriage of MRE. Eight travellers in this study reported an episode of urinary tract infection after their return, but no microbiological data were available [25]. In the study by Tängdén et al., five of 21 travellers remained carriers of MRE after six months. However, none of these participants reported clinical infections [17]. In the study of Kennedy et al., one person developed a urinary tract infection with a travel-related organism [18]. Kantele et al. performed a one-year laboratory-based follow-up and did not find any clinical samples with MRE [20].

\section{Rate of transmission to household members} Only one study screened household contacts for MRE after return of the index traveller. Household contacts were defined as persons who shared the same household with a participant on a regular basis. Two of 11 contacts were found MRE-positive [24]. Both carried a different ESBL-producing $E$. coli based on multilocus sequence typing (MLST) than the associated traveller.

\section{Limitations of the studies}

The quality of the studies and the susceptibility of bias between the studies were assessed. In all but one study, participants constituted a non-random sample of the general travelling population [17-21,23-27]. However, Angelin et al. studied healthcare students working or studying abroad [22]. Studies were performed on three different continents. Travel destinations and travel behaviour may differ considerably between different nationalities and age groups. Including co-travellers, as done in all studies except Paltansing et al. and Ruppé et al., can result in similar travel behaviour and therefore, similar risk factors. Overall, the main outcome was not influenced by recall or interviewer bias. For other outcomes such as risk factors, the risk of recall bias or interviewer bias was low because of the use of self-administered questionnaires.

Every study had participants lost to follow-up for post-travel stool samples and follow-up stool samples. Asymptomatic faecal carriage of MRE is probably not related to loss to follow-up, therefore, the risk of information bias is small. Ruppé et al. calculated posttravel MRE carriage as those travellers with persisting MRE carriage divided by all travellers with MRE acquisition plus all travellers without MRE post-travel [25]. However, travellers without MRE were not included in the follow-up. As a result, local MRE acquisition was not included in the calculated post-travel MRE carriage prevalence. Therefore the true prevalence can be assumed to be higher.

In five studies, travellers visited multiple regions or even continents during their trip $[17-20,27]$. In these travellers, it was not possible to attribute MRE prevalence or MRE acquisition to a certain geographical region. However, travellers in these studies were included in the MRE prevalence or MRE acquisition rates of more than one geographical region, which may have introduced information bias.

Seven studies used stool samples for detection of MRE $[17,19-21,23,25,27]$ and three studies used rectal or perianal swabs for detection of MRE $[18,24,26]$. This might have influenced detection of MRE carriage. 


\begin{tabular}{|c|c|c|c|c|c|}
\hline o & $\begin{array}{l}\frac{\pi}{2} \\
\frac{5}{0} \\
0 \\
2\end{array}$ & $\begin{array}{l}\frac{\pi}{5} \\
\frac{\pi}{0} \\
\frac{0}{2}\end{array}$ & $\begin{array}{l}\frac{\pi}{5} \\
\frac{\pi}{0} \\
\frac{0}{2}\end{array}$ & $\begin{array}{l}\frac{\pi}{5} \\
\frac{5}{0} \\
0 \\
2\end{array}$ & $\begin{array}{l}\frac{\pi}{10} \\
\frac{15}{0} \\
\frac{0}{2}\end{array}$ \\
\hline 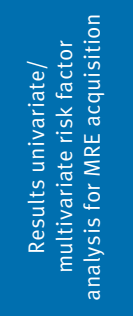 & 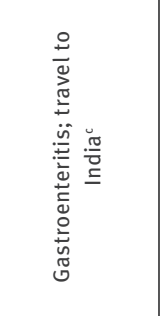 & 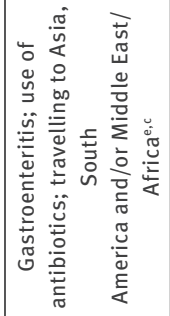 & 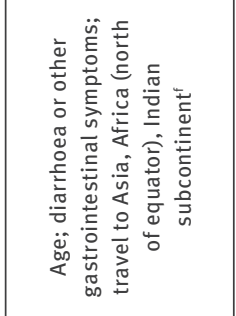 & 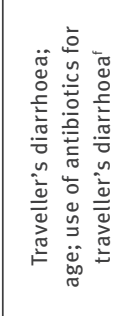 & $\begin{array}{l}\frac{5}{10} \\
\frac{\pi}{0} \\
\frac{0}{2}\end{array}$ \\
\hline 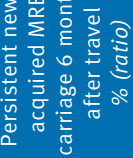 & $\triangle \stackrel{\bar{N}}{\sqrt{\omega}}$ & ○ & $\begin{array}{l}\frac{0}{\pi} \\
\frac{\pi}{0} \\
\frac{0}{2}\end{array}$ & $\begin{array}{l}\frac{\pi}{5} \\
\frac{\pi}{0} \\
\frac{0}{2}\end{array}$ & $\begin{array}{l}\frac{\pi}{10} \\
\frac{10}{0} \\
\frac{0}{2}\end{array}$ \\
\hline 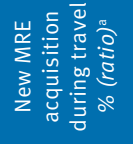 & 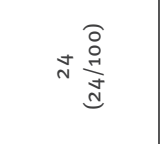 & 효 & 勇 & 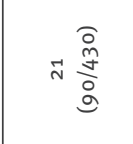 & $\stackrel{N}{\frac{\pi}{N}}$ \\
\hline 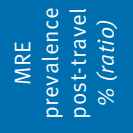 & $\begin{array}{l}\frac{\pi}{\pi} \\
\frac{\pi}{0} \\
\frac{0}{2}\end{array}$ & N & $\bar{m} \frac{\stackrel{D}{\tilde{N}}}{\frac{N}{N}}$ & $\approx \frac{\bar{o}}{\tilde{y}}$ & 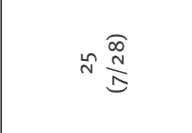 \\
\hline 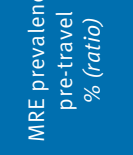 & 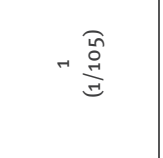 & r & 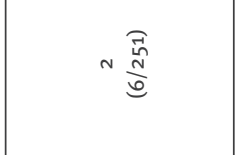 & $-\frac{\widehat{O}}{\sqrt[y]{\omega}}$ & 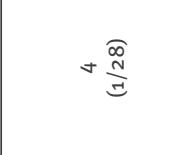 \\
\hline 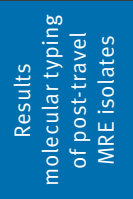 & $\begin{array}{l}\frac{\pi}{\pi} \\
\frac{\pi}{0} \\
2\end{array}$ & $\begin{array}{l}\frac{\pi}{5} \\
\frac{5}{50} \\
\text { O }\end{array}$ & $\begin{array}{l}\frac{\pi}{5} \\
\frac{\pi}{50} \\
\frac{0}{2}\end{array}$ & $\begin{array}{l}\frac{\pi}{5} \\
\frac{5}{0} \\
\text { 20 }\end{array}$ & 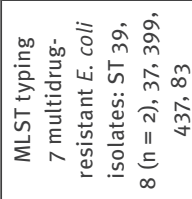 \\
\hline 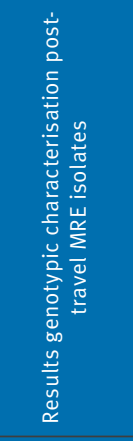 & 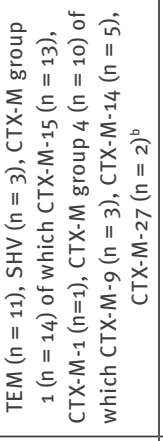 & 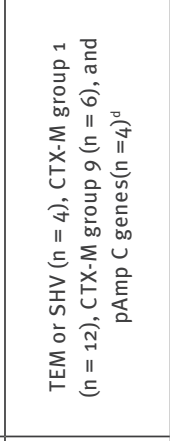 & 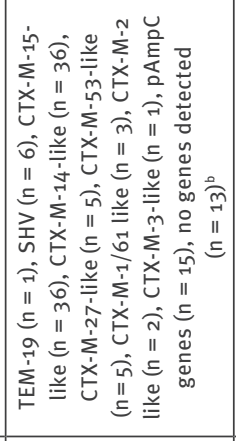 & 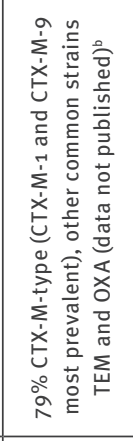 & 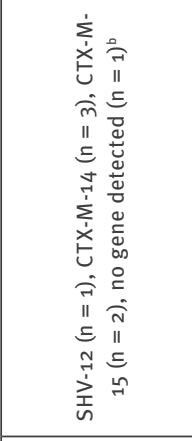 \\
\hline 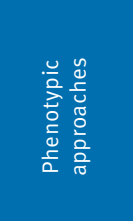 & 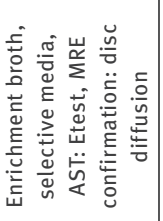 & 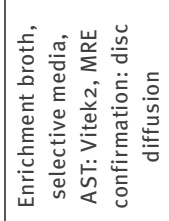 & 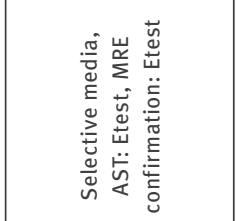 & 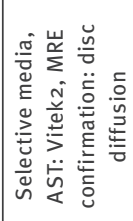 & 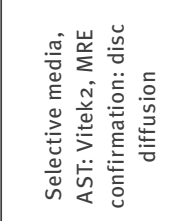 \\
\hline 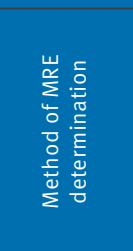 & 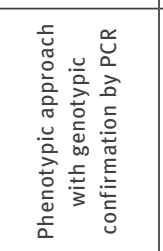 & 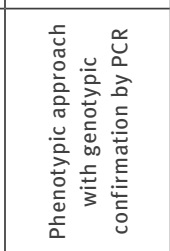 & 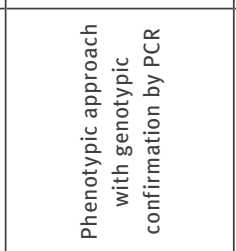 & 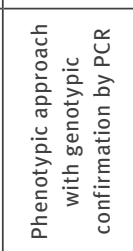 & 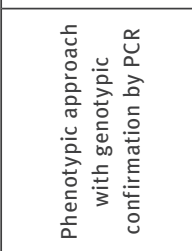 \\
\hline 咅 & 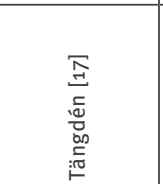 & 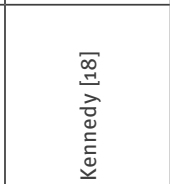 & 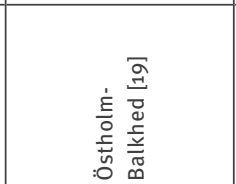 & 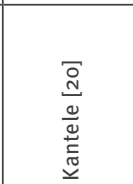 & 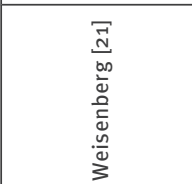 \\
\hline
\end{tabular}

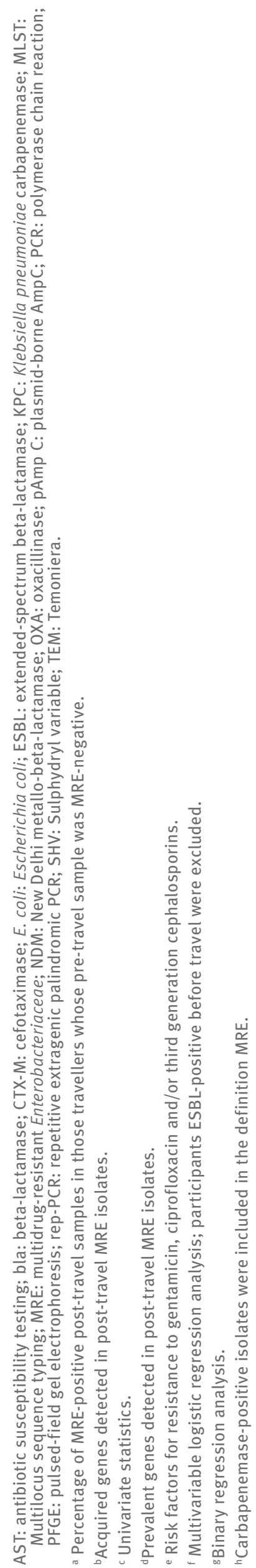




\begin{tabular}{|c|c|c|c|c|}
\hline 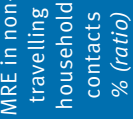 & $\begin{array}{l}\frac{\pi}{0} \\
\frac{\pi}{0} \\
\frac{0}{2}\end{array}$ & $\begin{array}{l}\frac{\pi}{0} \\
\frac{\pi}{5} \\
\frac{0}{2}\end{array}$ & $\stackrel{\infty}{\stackrel{F}{a}}$ & $\begin{array}{l}\frac{\pi}{\tilde{J}} \\
\frac{5}{0} \\
\frac{0}{2}\end{array}$ \\
\hline 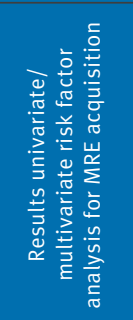 & 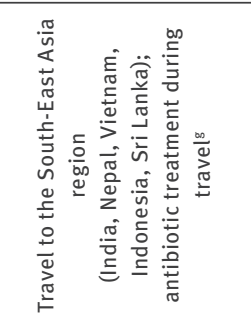 & 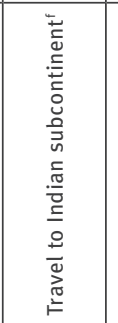 & 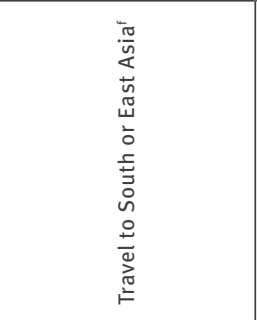 & 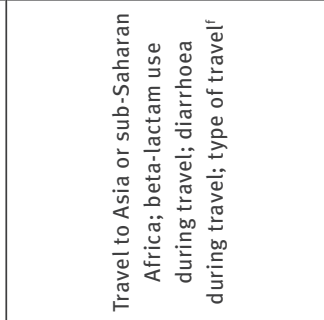 \\
\hline 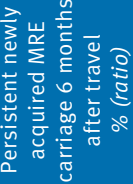 & $\begin{array}{l}\frac{\tilde{5}}{\frac{\pi}{5}} \\
\frac{0}{2}\end{array}$ & $\begin{array}{l}\frac{0}{\pi} \\
\frac{\pi}{0} \\
0 \\
2\end{array}$ & $=\frac{\widehat{M}}{\underline{g}}$ & 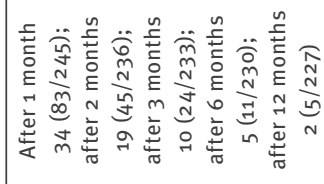 \\
\hline 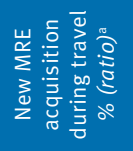 & 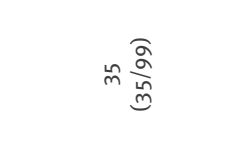 & m & 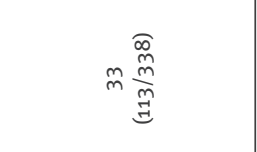 & 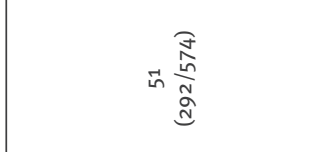 \\
\hline 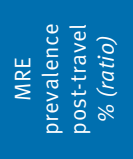 & 品 & 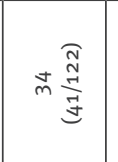 & 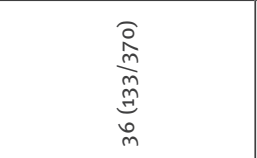 & $\begin{array}{l}\frac{\pi}{\pi} \\
\frac{\pi}{0} \\
\frac{0}{2}\end{array}$ \\
\hline 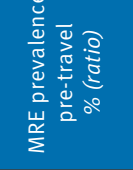 & $\wedge \frac{\widehat{a}}{5}$ & 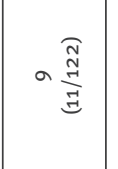 & 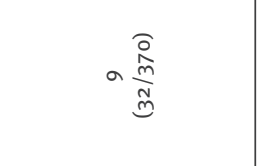 & $\approx \underset{\sim}{\stackrel{\partial}{\stackrel{D}{F}}}$ \\
\hline 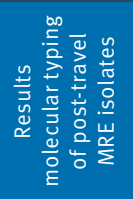 & $\begin{array}{l}\frac{5}{\frac{\pi}{50}} \\
\frac{0}{2}\end{array}$ & $\begin{array}{l}\frac{\pi}{\pi} \\
\frac{\pi}{0} \\
\frac{0}{2}\end{array}$ & 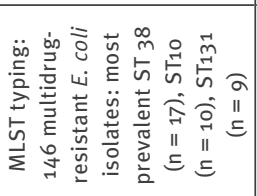 & $\begin{array}{l}\frac{\pi}{5} \\
\frac{\pi}{50} \\
\frac{0}{2}\end{array}$ \\
\hline 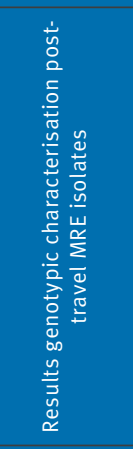 & $\begin{array}{l}\frac{\pi}{5} \\
\frac{\pi}{0} \\
2 \\
2\end{array}$ & 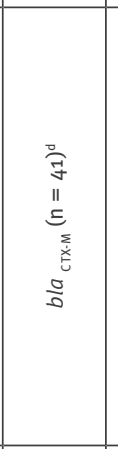 & 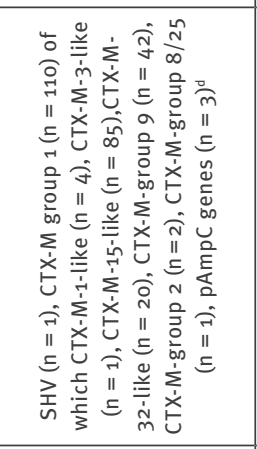 & 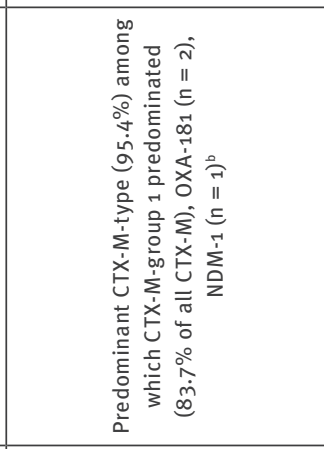 \\
\hline 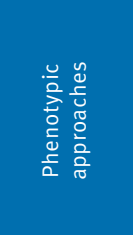 & 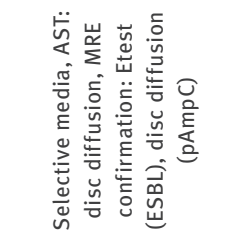 & $\begin{array}{l}\frac{\pi}{2} \\
\frac{5}{0} \\
\frac{0}{2}\end{array}$ & 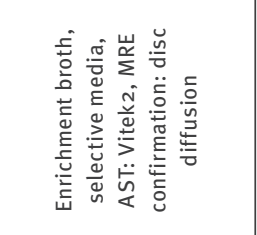 & 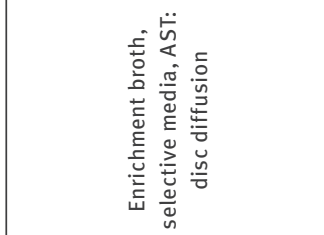 \\
\hline 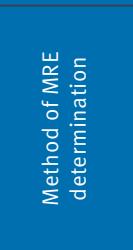 & 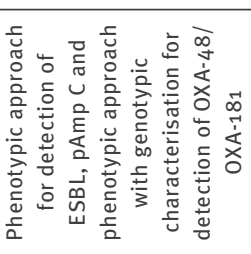 & 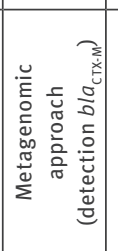 & 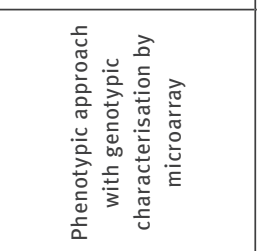 & 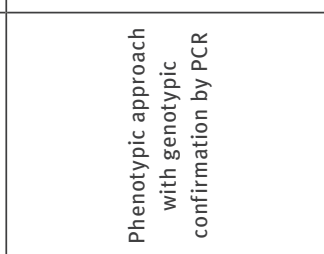 \\
\hline 㐔 & 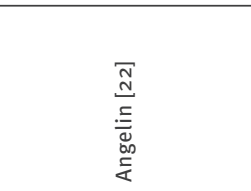 & 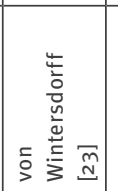 & 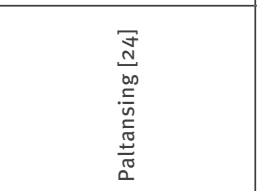 & 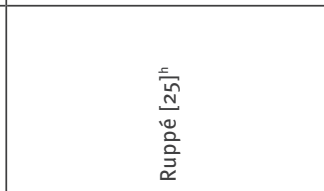 \\
\hline
\end{tabular}

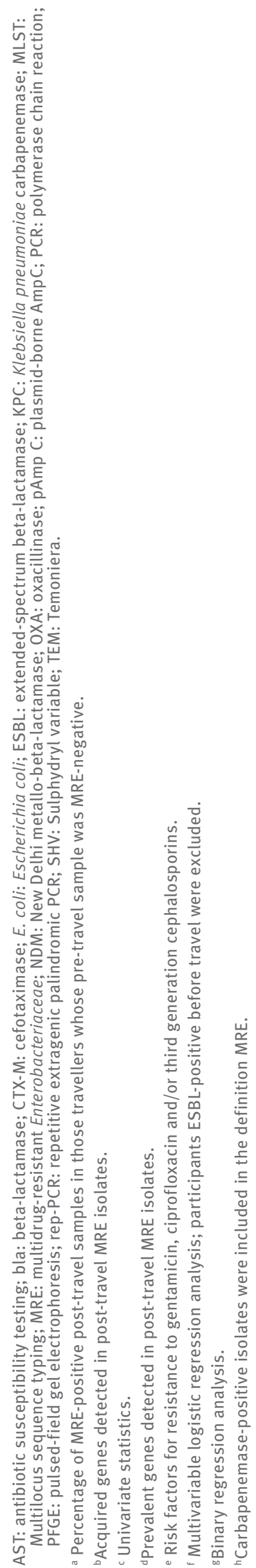




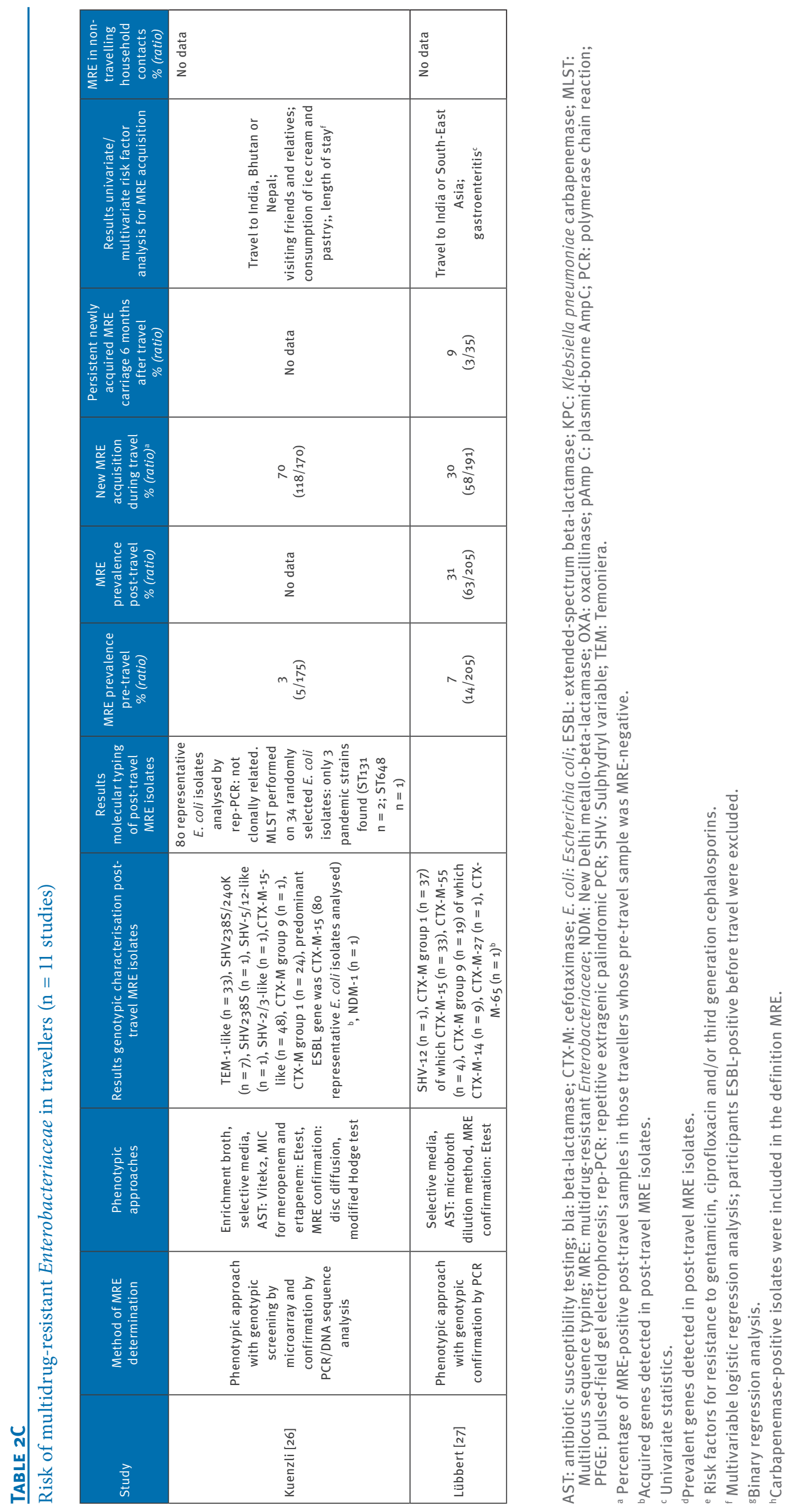


TABLE 3

Proportion of travellers who acquired multidrug-resistant Enterobacteriaceae, by travel destination ( $\mathrm{n}=11$ studies)

\begin{tabular}{|c|c|c|c|c|c|c|c|c|}
\hline Study & $\begin{array}{l}\text { Southern } \\
\text { Asia } \\
\% \text { (ratio) }\end{array}$ & $\begin{array}{c}\text { Asia except } \\
\text { southern Asia } \\
\% \text { (ratio) }\end{array}$ & $\begin{array}{c}\text { Northern Africa } \\
\% \text { (ratio) }\end{array}$ & $\begin{array}{c}\text { Sub-Saharan } \\
\text { Africa } \\
\% \text { (ratio) }\end{array}$ & $\begin{array}{c}\text { South and } \\
\text { Central America } \\
\% \text { (ratio) }\end{array}$ & $\begin{array}{l}\text { North } \\
\text { America } \\
\% \text { (ratio) }\end{array}$ & $\begin{array}{l}\text { Europe } \\
\% \text { (ratio) }\end{array}$ & $\begin{array}{l}\text { Oceania } \\
\% \text { (ratio) }\end{array}$ \\
\hline Tängdén [17] $]^{\mathrm{a}, \mathrm{b}}$ & $\begin{array}{l}78 \\
(7 / 9)\end{array}$ & $\begin{array}{c}29 \\
(10 / 34)\end{array}$ & $\begin{array}{c}33 \\
(4 / 12)\end{array}$ & $4(1 / 23)$ & $\begin{array}{c}0 \\
(0 / 7)\end{array}$ & $\begin{array}{c}0 \\
(0 / 2)\end{array}$ & $\begin{array}{c}13 \\
(2 / 16)\end{array}$ & - \\
\hline Kennedy $[18]^{\mathrm{a}, \mathrm{c}}$ & $\begin{array}{c}57 \\
(8 / 14)\end{array}$ & $\begin{array}{c}25 \\
(21 / 85)\end{array}$ & $\begin{array}{c}33 \\
(1 / 3)\end{array}$ & $\begin{array}{c}0 \\
(0 / 2)\end{array}$ & $\begin{array}{c}20 \\
(1 / 5)\end{array}$ & $\begin{array}{c}20 \\
(2 / 10)\end{array}$ & $\begin{array}{c}14 \\
(3 / 21)\end{array}$ & $\begin{array}{c}0 \\
(0 / 2)\end{array}$ \\
\hline $\begin{array}{l}\text { Östholm-Balkhed } \\
{[19]^{\mathrm{a}, \mathrm{b}}}\end{array}$ & $\begin{array}{c}71 \\
(10 / 14)\end{array}$ & $\begin{array}{c}43 \\
(26 / 60)\end{array}$ & $57(17 / 30)$ & $\begin{array}{c}21 \\
(15 / 71)\end{array}$ & $\begin{array}{c}16 \\
(5 / 31)\end{array}$ & $\begin{array}{c}0 \\
(0 / 15)\end{array}$ & $\begin{array}{c}0 \\
(0 / 15)\end{array}$ & No data \\
\hline Kantele [20] $]^{\mathrm{b}, \mathrm{d}}$ & $\begin{array}{c}46 \\
(28 / 61)\end{array}$ & $\begin{array}{c}32 \\
(37 / 116)\end{array}$ & $\begin{array}{c}67 \\
(2 / 3)\end{array}$ & $\begin{array}{c}12 \\
(23 / 193)\end{array}$ & $\begin{array}{c}0 \\
(0 / 40)\end{array}$ & $\begin{array}{c}0 \\
(0 / 2)\end{array}$ & $\begin{array}{c}0 \\
(0 / 15)\end{array}$ & No data \\
\hline Weisenberg [21] ${ }^{\mathrm{b}}$ & $\begin{array}{c}29 \\
(2 / 7)\end{array}$ & $\begin{array}{c}25 \\
(1 / 4)\end{array}$ & $\begin{array}{c}33 \\
(1 / 3)\end{array}$ & $\begin{array}{c}13 \\
(1 / 8)\end{array}$ & $\begin{array}{c}33 \\
(2 / 6)\end{array}$ & No data & No data & No data \\
\hline Angelin [22] & $\begin{array}{c}63 \\
(25 / 40)\end{array}$ & $\begin{array}{c}67 \\
(6 / 9)\end{array}$ & No data & $\begin{array}{c}10 \\
(4 / 40)\end{array}$ & $\begin{array}{c}0 \\
(0 / 5)\end{array}$ & $\begin{array}{c}0 \\
(0 / 4)\end{array}$ & No data & No data \\
\hline $\begin{array}{l}\text { von Wintersdorff } \\
{[23]^{c}}\end{array}$ & $\begin{array}{c}58 \\
(18 / 31)\end{array}$ & $\begin{array}{c}20 \\
(6 / 29)\end{array}$ & $\begin{array}{c}31 \\
(5 / 16)\end{array}$ & $\begin{array}{c}29 \\
(5 / 17)\end{array}$ & $\begin{array}{c}0 \\
(0 / 10)\end{array}$ & No data & $\begin{array}{c}17 \\
(1 / 6)\end{array}$ & No data \\
\hline Paltansing $[24]^{\mathrm{b}, \mathrm{e}}$ & $\begin{array}{c}72 \\
(18 / 25)\end{array}$ & $41(60 / 146)$ & $\begin{array}{c}40 \\
(4 / 10)\end{array}$ & $\begin{array}{c}24 \\
(20 / 82)\end{array}$ & $\begin{array}{c}15 \\
(9 / 60)\end{array}$ & No data & No data & No data \\
\hline Ruppé [25] ${ }^{f}$ & $\begin{array}{c}88 \\
(53 / 60)\end{array}$ & $\begin{array}{c}66 \\
(61 / 93)\end{array}$ & No data & $\begin{array}{c}49 \\
(89 / 182)\end{array}$ & $\begin{array}{c}31 \\
(48 / 155)\end{array}$ & No data & No data & $\begin{array}{c}0 \\
(0 / 2)\end{array}$ \\
\hline Kuenzli [26] ${ }^{\mathrm{b}}$ & 69 & No data & No data & No data & No data & No data & No data & No data \\
\hline Lübbert [27] $]^{\mathrm{a}, \mathrm{b}}$ & $\begin{array}{c}72 \\
(13 / 18)^{g}\end{array}$ & $\begin{array}{c}33 \\
(24 / 73)^{g}\end{array}$ & No data & $\begin{array}{c}24 \\
(19 / 78)\end{array}$ & $\begin{array}{c}8 \\
(6 / 78)\end{array}$ & $\begin{array}{c}0 \\
(0 / 2)\end{array}$ & $\begin{array}{c}20 \\
(2 / 10)\end{array}$ & No data \\
\hline
\end{tabular}

MRE: multidrug-resistant Enterobacteriaceae.

${ }^{a}$ Travellers visiting more than one region are categorised in all the visited geographical regions.

${ }^{b}$ Study reports data on MRE acquisition in travellers.

c Study reports data on MRE prevalence in travellers.

${ }^{d}$ Travellers visiting more than one region are categorised in the geographical region with the longest stay for this study.

e One traveller who visited Iran is categorised in Asia instead of Southern Asia.

${ }^{f} 42$ travellers visited more than one country in Asia and may be represented in more than one column in the Table; 28 of them acquired MRE.

${ }^{g}$ Exact numbers unpublished.

Southern Asia: Afghanistan, Bangladesh, Bhutan, India, Iran, Maldives, Nepal, Pakistan, Sri Lanka.

Asia (without southern Asia): Armenia, Azerbaijan, Bahrain, Brunei, Cambodia, China, Cyprus, Georgia, Hong Kong, Indonesia, Iraq, Israel, Jordan, Japan, Kazakhstan, Kuwait, Kyrgyzstan, Laos, Lebanon, Mongolia, Malaysia, Myanmar, North Korea, Oman, Philippines, Qatar, Saudi Arabia, South Korea, Singapore, Palestine, Syria, Tajikistan, Thailand, Timor-Leste, Turkey, Turkmenistan, United Arab Emirates, Uzbekistan, Viet Nam, Yemen.

Northern Africa: Algeria, Egypt, Libya, Morocco, Sudan, Tunisia, Western Sahara.

Sub-Saharan Africa: Angola, Benin, Botswana, Burkina Faso, Burundi, Cameroon, Cape Verde, Central African Republic, Chad, Comoros, Congo (Brazzaville), Côte d'Ivoire, Democratic Republic of the Congo, Djibouti, Equatorial Guinea, Eritrea, Ethiopia, Gabon, Ghana, Guinea, Guinea-Bissau, Kenya, Lesotho, Liberia, Madagascar, Malawi, Mali, Mauritania, Mauritius, Mozambique, Namibia, Niger, Nigeria, Réunion, Rwanda, São Tomé and Príncipe, Senegal, Seychelles, Sierra Leone, Somalia, South Africa, Sudan, Swaziland, Tanzania, The Gambia, Togo, Uganda, Zambia, Zimbabwe.

South and Central America: Anguilla, Antigua and Barbuda, Argentina, Aruba, Bahamas, Barbados, Belize, Bolivia, Bonaire, Sint Eustatius and Saba, Brazil, British Virgin Islands, Cayman Islands, Chile, Colombia, Costa Rica, Cuba, Curaçao, Dominica, Dominican Republic, Ecuador, El Salvador, Falkland Islands, French Guiana, Grenada, Guadeloupe, Guatemala, Guyana, Haiti, Honduras, Jamaica, Martinique, Mexico, Montserrat, Nicaragua, Panama, Paraguay, Peru, Puerto Rico, Saint Kitts and Nevis, Saint Lucia, Saint Martin, Saint Vincent and the Grenadines, Saint-Barthélemy, Sint Maarten, Suriname, Trinidad and Tobago, Turks and Caicos Islands, US Virgin Islands, Uruguay, Venezuela.

North America: Bermuda, Canada, Greenland, Saint Pierre and Miquelon, United States.

Europe: Åland Islands, Albania, Andorra, Austria, Belarus, Belgium, Bosnia and Herzegovina, Bulgaria, Channel Islands, Croatia, Czech Republic, Denmark, Estonia, Faeroe Islands, Finland, the former Yugoslav Republic of Macedonia, France, Germany, Gibraltar, Greece, the Holy See, Hungary, Iceland, Ireland, Isle of Man, Italy, Latvia, Liechtenstein, Lithuania, Luxembourg, Malta, Monaco, Montenegro, Netherlands, Norway, Poland, Portugal, Moldova, Romania, Russia, San Marino, Serbia, Slovakia, Slovenia, Spain, Svalbard and Jan Mayen, Sweden, Switzerland, Ukraine, United Kingdom.

Oceania: American Samoa, Australia, Cook Islands, Fiji, French Polynesia, Guam, Kiribati, Marshall Islands, Micronesia, Nauru, New Caledonia, New Zealand, Niue, Norfolk Island, Northern Mariana Islands, Palau, Papua New Guinea, Pitcairn Islands, Samoa, Solomon Islands, Tokelau, Tonga, Tuvalu, Vanuatu, Wallis and Futuna. 
TABLE 4

Antibiotic drug resistance of newly acquired multidrug-resistant Enterobacteriaceae in travellers ( $\mathrm{n}=11$ studies)

\begin{tabular}{|c|c|c|c|c|c|c|c|c|c|}
\hline Study & $\begin{array}{c}\text { Ciprofloxacin } \\
\% \text { (ratio) }\end{array}$ & $\begin{array}{l}\text { Cotrimoxazole } \\
\% \text { (ratio) }\end{array}$ & $\begin{array}{l}\text { Gentamicin } \\
\% \text { (ratio) }\end{array}$ & $\begin{array}{l}\text { Amikacin } \\
\% \text { (ratio) }\end{array}$ & $\begin{array}{l}\text { Tobramycin } \\
\% \text { (ratio) }\end{array}$ & $\begin{array}{l}\text { Carbapenem } \\
\% \text { (ratio) }\end{array}$ & $\begin{array}{l}\text { Nitrofurantoin } \\
\% \text { (ratio) }\end{array}$ & $\begin{array}{l}\text { Colistin } \\
\% \text { (ratio) }\end{array}$ & $\begin{array}{l}\text { Fosfomycin } \\
\% \text { (ratio) }\end{array}$ \\
\hline Tängdén [17] ${ }^{\mathrm{a}}$ & $50^{b}$ & $\begin{array}{c}79 \\
(19 / 24) \\
\end{array}$ & $45^{\mathrm{b}}$ & No data & $38^{b}$ & $0^{b}$ & $\mathrm{o}^{\mathrm{b}}$ & No data & $8.0^{\mathrm{b}}$ \\
\hline Kennedy $[18]^{c}$ & $\begin{array}{c}55 \\
(12 / 22) \\
\end{array}$ & No data & $\begin{array}{c}50 \\
(11 / 22) \\
\end{array}$ & No data & $\begin{array}{c}59 \\
(13 / 22) \\
\end{array}$ & No data & No data & No data & No data \\
\hline $\begin{array}{l}\text { Östholm- } \\
\text { Balkhed [19] }\end{array}$ & $\begin{array}{c}31 \\
(36 / 116)\end{array}$ & $\begin{array}{c}70 \\
(81 / 116)\end{array}$ & $\begin{array}{c}41 \\
(48 / 116)\end{array}$ & $\begin{array}{c}2 \\
(2 / 116)\end{array}$ & $\begin{array}{c}46 \\
(53 / 116)\end{array}$ & $\begin{array}{c}0 \\
(0 / 116)\end{array}$ & $\begin{array}{c}7 \\
(8 / 116)\end{array}$ & No data & $\begin{array}{c}3 \\
(3 / 116)\end{array}$ \\
\hline Kantele [20] & No data & No data & No data & No data & No data & No data & No data & No data & No data \\
\hline $\begin{array}{l}\text { Weisenberg } \\
{[21]^{a^{a}}}\end{array}$ & $\begin{array}{r}43 \\
(3 / 7)^{d} \\
\end{array}$ & $\begin{array}{c}86 \\
(6 / 7) \\
\end{array}$ & $\begin{array}{c}43 \\
(3 / 7) \\
\end{array}$ & No data & No data & $\begin{array}{c}0 \\
(0 / 7) \\
\end{array}$ & No data & No data & No data \\
\hline Angelin [22] & $\begin{array}{r}57 \\
(28 / 49) \\
\end{array}$ & $75^{\mathrm{b}}$ & $30^{\mathrm{b}}$ & No data & No data & $\begin{array}{c}0 \\
(0 / 49)\end{array}$ & $2^{b}$ & No data & No data \\
\hline $\begin{array}{l}\text { von } \\
\text { Wintersdorff } \\
{[23]^{e}}\end{array}$ & $\begin{array}{c}37 \\
(45 / 122) \\
q n r B \\
56 \\
(68 / 122) \\
\text { qnrS } \\
\end{array}$ & No data & $\begin{array}{c}71 \\
(86 / 122) \\
\operatorname{aac}\left(6^{\prime}\right)- \\
\operatorname{aph}(2, ')\end{array}$ & $\begin{array}{c}71 \\
(86 / 122) \\
\operatorname{aac}\left(6^{\prime}\right)- \\
\operatorname{aph}\left(2^{\prime \prime}\right)\end{array}$ & $\begin{array}{c}71 \\
(86 / 122) \\
\text { aac(6')- } \\
\operatorname{aph}\left(2^{\prime}\right)\end{array}$ & $\begin{array}{c}0 \\
(\mathrm{o} / 122) \\
\text { bla }_{\mathrm{NDM}}\end{array}$ & No data & No data & No data \\
\hline $\begin{array}{l}\text { Paltansing } \\
{[24]^{\mathrm{f}}}\end{array}$ & 36 & 67 & 35 & No data & 37 & o & 29 & o & No data \\
\hline Ruppé [25] & No data & No data & No data & No data & No data & $\begin{array}{c}0.6 \\
(3 / 526)^{g} \\
\end{array}$ & No data & No data & No data \\
\hline Kuenzli [26]a & $\begin{array}{c}41 \\
(64 / 157) \\
\end{array}$ & $\begin{array}{c}49 \\
(77 / 157) \\
\end{array}$ & No data & $\begin{array}{c}5 \\
(7 / 157) \\
\end{array}$ & $\begin{array}{c}18 \\
(28 / 157) \\
\end{array}$ & $\begin{array}{c}0 \\
(0 / 157)\end{array}$ & $\begin{array}{c}2 \\
(3 / 157) \\
\end{array}$ & $\begin{array}{c}0 \\
(0 / 157) \\
\end{array}$ & $\begin{array}{c}0.6 \\
(1 / 157) \\
\end{array}$ \\
\hline Lübbert [27] & $\begin{array}{c}43 \\
(25 / 58) \\
\end{array}$ & $\begin{array}{c}83 \\
(48 / 58) \\
\end{array}$ & $\begin{array}{c}17 \\
(10 / 58) \\
\end{array}$ & $2^{\mathrm{b}}$ & $22^{\mathrm{b}}$ & $0^{b}$ & No data & $0^{\mathrm{b}}$ & $16^{\mathrm{b}}$ \\
\hline
\end{tabular}

bla: beta-lactamase; CPE: carbapenemase-producing Enterobacteriaceae; ESBL: extended-spectrum beta-lactamase.

a Resistance among acquired ESBL-positive isolates detected in post-travel samples.

${ }^{b}$ Data extracted from bar chart, exact numbers unpublished.

c Resistance among prevalent ESBL-positive isolates detected in post-travel samples.

${ }^{d}$ Percentage of susceptibility to levofloxacin.

e Prevalent resistance genes in faecal samples post-travel.

${ }^{f}$ Resistance among prevalent ESBL-positive isolates detected in pre- and post-travel samples.

$\mathrm{g}$ Three acquired CPE detected in post-travel samples.

\section{Discussion}

In this systematic review we found a high prevalence of faecal carriage of MRE after international travel. The highest prevalence of MRE was observed in isolates from travellers returning from southern Asia, with up to $88 \%$ acquisition of MRE. In addition to the antibiotics not effective against MRE, an alarmingly high prevalence of resistance to other commonly used antibiotics such as cotrimoxazole (49-86\%), ciprofloxacin (31-57\%) and aminoglycosides (gentamicin $17-71 \%$ ) was observed in ESBL-positive isolates in travellers in all studies [17-27].

Returning international travellers with MRE may introduce these microorganisms in their home countries. This may cause community-onset infections with MRE in patients without obvious risk factors transmitted by healthy carriers through food or person-to-person contact [9]. Infections caused by MRE are associated with poorer outcome and a higher overall mortality rate than infections caused by susceptible bacteria [28]. In this review, all studies showed an increased prevalence of faecal carriage of ESBL after international travel. It is not possible to evaluate the proportion of travellers who will develop infection with these resistant bacteria. However, studies have demonstrated that international travel is a risk factor associated with developing an infection with an MRE $[11,12,29]$.

Many countries have infection prevention and control guidelines to detect and treat multidrug-resistant organisms (MDROs) including MRE [30]. In countries with low prevalence of MRE, infection prevention and control guidelines mainly include strategies for early identification and isolation of patients recently hospitalised in foreign hospitals $[30,31]$. Patients with a recent history of travel to MRE-endemic areas but not admitted to healthcare facilities abroad are not normally considered at risk for carriage of MDROs. However, in hospitalised patients with a recent history of travel, increased rates of carriage of MRE have been observed $[10,29,30]$. Physicians should be aware of the risk that patients with recent travel to areas with high faecal carriage of MRE, as presented in this review, may introduce MRE to the hospital. Routine screening 
for MRE seems indicated in such patients. Furthermore, empiric antibiotic therapy may fail when an infection by MRE is not taken into account. Therefore, careful recording of travel history needs to be incorporated in each patient evaluation. As shown in this review, there is also an increased risk of resistance against other antibiotics in travellers with MRE carriage. It is likely that this is caused by multiple genes, each encoding resistance to different classes of antibiotics, which are often found on the same bacterial mobile genetic element (e.g. a plasmid) [32]. As a result, other antibiotics, such as aminoglycosides, will also fail in many MRE-positive patients.

Of all MDROs, emergence of CPE is most worrisome because of the limited treatment options for these infections. NDM-1-producing Enterobacteriaceae have been found in environmental samples in endemic regions [33]. CPE (NDM-1) in patients from the United Kingdom with a recent history of travelling or medical tourism to India are already an important public health problem [8]. Case reports have also demonstrated acquisition of CPE in travellers without contact with medical healthcare facilities $[34,35]$. In this review, four travellers from India were carrying a carbapenemase-producing $E$. coli $[25,26]$. Preliminary results of the Carriage Of Multiresistant Bacteria After Travel (COMBAT) study, a large-scale multicentre longitudinal cohort study conducted in the Netherlands among 2001 travellers, show acquisition of CPE in four travellers [36].

There are, besides the destination of travel, additional risk factors for acquiring MRE during travel. Antibiotic therapy was found to increase the risk $[20,22]$. In five studies, traveller's diarrhoea or gastroenteritis were associated with an increased risk of MRE acquisition during travel $[17-20,25]$. Also, in one study, meticulous hand hygiene or strict consumption of bottled water did not lower the risk of acquiring MRE [22]. Therefore, it is not clear whether hygiene-related travel advice will decrease faecal carriage of MRE. Surprisingly, healthcare-related activities did not pose an increased risk of acquiring MRE in one study [22].

MRE and CPE could also be carried by food. International spread of these bacteria by food supply has been reported [37]. In this review, only one study showed that food consumption (ice cream and pastry) was associated with MRE carriage in travellers to southern Asia, whereas most of the studies did not focus on dietary patterns during travel.

One limitation of this review is the recruitment of travellers from travel clinics only, resulting in inclusion of very few travellers with European destinations. Some European countries such as Greece and Cyprus are also endemic for MRE and popular travel destinations [34]. In addition, travellers visiting their country of origin, especially Morocco and Turkey usually do not ask for a pre-travel consultation, although these countries are endemic for MRE and CPE [34]. It is not clear whether not including these patients may have led to an underor overestimation of MRE acquisition.

Another limitation is the lack of sufficient data regarding the duration of carriage and the transmission among non-travelling household members. The study by Ruppé et al. suggests that three months after return, MRE carriage is comparable with the baseline prevalence before travelling. However, the study did not include baseline prevalence in the follow-up. The COMBAT study will address some of these questions [38].

\section{Conclusion}

International travel is a major risk factor for acquisition of MRE. This risk is particularly high after travelling to (southern) Asia and in persons with travel-related diarrhoea and antibiotic use. Carriage of MRE-positive isolates is also associated with a high risk of resistance to ciprofloxacin, cotrimoxazole and aminoglycosides. Further research is needed to assess duration of carriage, spread to household contacts and whether introduction of MRE results in an increase of MRE infections. Our results, combined with the worldwide emergence of CPE, further stress the importance of infection prevention and control guidelines.

\section{Acknowledgements}

We thank Wichor M. Bramer of Erasmus MC Medical Library for performing the literature search. We thank Karina Kennedy, Scott Weisenberg, Anita Hällgren, Christian von Wintersdorff, Anu Kantele, Esther Kuenzli, Thomas Tängdén and Christoph Lübbert for providing additional data concerning their studies.

Conflict of interest

None declared.

Authors' contributions

Robert-Jan Hassing: This author made substantial contributions to conception and design, acquisition of data and analysis and interpretation of data; this author participated in drafting the article; this authors gave final approval of the version to be submitted and any revised version. Jelmer Alsma: This author made substantial contributions to conception and design, acquisition of data and analysis and interpretation of data; this author participated in drafting the article; this authors gave final approval of the version to be submitted and any revised version. Maris S. Arcilla: This author made substantial contributions to acquisition of data and analysis and interpretation of data; this author participated in drafting the article; this author gave final approval of the version to be submitted and any revised version. Bruno H. Stricker: This author made substantial contributions to conception and design and analysis and interpretation of data; this author participated in revising the article critically for important intellectual content; this authors gave final approval of the version to be submitted and any revised version. Perry J. van Genderen: This author made substantial contributions to conception and design; this author participated in revising the article critically for important intellectual content; this authors gave final approval of the version 
to be submitted and any revised version. Annelies Verbon: This author made substantial contributions to conception and design and analysis and interpretation of data; this author participated in revising the article critically for important intellectual content; this authors gave final approval of the version to be submitted and any revised version.

\section{References}

1. World Tourism Organization (UNWTO). UNWTO

tourism highlights, 2014 edition. Madrid: UNTWO; 2014. Available from: http://www.e-unwto.org/doi/ pdf/10.18111/9789284416226

2. Freedman DO, Weld LH, Kozarsky PE, Fisk T, Robins R, von Sonnenburg F, et al. Spectrum of disease and relation to place of exposure among ill returned travelers. N Engl J Med. 2006;354(2):119-30. DOI: 10.1056/NEJMoa051331 PMID: 16407507

3. Steffen R, deBernardis C, Baños A. Travel epidemiology--a global perspective.Int J Antimicrob Agents. 2003;21(2):89-95. DOI: 10.1016/S0924-8579(02)00293-5 PMID: 12615369

4. Chen LH, Wilson ME. The role of the traveler in emerging infections and magnitude of travel.Med Clin North Am. 2008;92(6):1409-32.

5. Wilson ME. The traveller and emerging infections: sentinel, courier, transmitter.J Appl Microbiol. 2003:94 Suppl;1S-11S. DOI: 10.1046/j.1365-2672.94.S1.1.x PMID: 12675931

6. Woodford N. Unwanted souvenirs: travel and multi-resistant bacteria.J Travel Med. 2011:18(5):297-8. DOI: 10.1111/j.1708. 8305.2011.00541.x PMID: 21896091

7. Woerther PL, Burdet C, Chachaty E, Andremont A. Trends in human fecal carriage of extended-spectrum $\beta$-lactamases in the community: toward the globalization of CTX-M.Clin Microbiol Rev. 2013;26(4):744-58. DOI: 10.1128/CMR.00023-13 PMID: 24092853

8. Kumarasamy KK, Toleman MA, Walsh TR, Bagaria J, Butt $F$, Balakrishnan R, et al. Emergence of a new antibiotic resistance mechanism in India, Pakistan, and the UK: a molecular, biological, and epidemiological study. Lancet Infect Dis. 2010;10(9):597-602. DOI: 10.1016/S1473-3099(10)70143-2 PMID: 20705517

9. Oteo J, Pérez-Vázquez M, Campos J. Extended-spectrum [beta]lactamase producing Escherichia coli: changing epidemiology and clinical impact.Curr Opin Infect Dis. 2010;23(4):320-6. DOI: 10.1097/QCO.ob013e3283398dc1 PMID: 20614578

10. Lausch KR, Fuursted K, Larsen CS, Storgaard M. Colonisation with multi-resistant Enterobacteriaceae in hospitalised Danish patients with a history of recent travel: a cross-sectional study.Travel Med Infect Dis. 2013;11(5):320-3. DOI: 10.1016/j. tmaid.2013.06.004 PMID: 23810306

11. Søraas A, Sundsfjord A, Sandven I, Brunborg C, Jenum PA. Risk factors for community-acquired urinary tract infections caused by ESBL-producing enterobacteriaceae--a case-control study in a low prevalence country.PLOS ONE. 2013;8(7):e69581. DOI: 10.1371/journal.pone.0069581 PMID: 23936052

12. Laupland KB, Church DL, Vidakovich J, Mucenski M, Pitout JD. Community-onset extended-spectrum beta-lactamase (ESBL) producing Escherichia coli: importance of international travel.J Infect. 2008;57(6):441-8. DOI: 10.1016/j.jinf.2008.09.034 PMID: 18990451

13. Moher D, Shamseer L, Clarke M, Ghersi D, Liberati A, Petticrew $M$, et al. Preferred reporting items for systematic review and meta-analysis protocols (PRISMA-P) 2015 statement. Syst Rev. 2015;4(1):1. DOI: 10.1186/2046-4053-4-1 PMID: 25554246

14. United Nations Statistics Division (UNSTATS). Composition of macro geographical (continental) regions, geographical sub-regions, and selected economic and other groupings. New York: UNSTATS. [Accessed: 1 Jun 2015]

15. von Elm E, Altman DG, Egger M, Pocock SJ, Gøtzsche PC, Vandenbroucke JP, et al. The Strengthening the Reporting of Observational Studies in Epidemiology (STROBE) statement: guidelines for reporting observational studies. PLoS Med. 2007;4(10):e296. DOI: 10.1371/journal.pmed.0040296 PMID: 17941714

16. Sanderson S, Tatt ID, Higgins JP. Tools for assessing quality and susceptibility to bias in observational studies in epidemiology: a systematic review and annotated bibliography.Int J Epidemiol. 2007;36(3):666-76. DOI: 10.1093/ ije/dymo18 PMID: 17470488

17. Tängdén T, Cars O, Melhus A, Löwdin E. Foreign travel is a major risk factor for colonization with Escherichia coli producing CTX-M-type extended-spectrum beta-lactamases: a prospective study with Swedish volunteers. Antimicrob Agents
Chemother. 2010;54(9):3564-8. DOI: 10.1128/AAC.00220-10 PMID: 20547788

18. Kennedy K, Collignon P. Colonisation with Escherichia coli resistant to "critically important" antibiotics: a high risk for international travellers. Eur J Clin Microbiol Infect Dis. 2010;29(12):1501-6. DOI: 10.1007/s10096-010-1031-y PMID: 20835879

19. Ostholm-Balkhed A, Tärnberg M, Nilsson M, Nilsson LE, Hanberger H, Hällgren A, et al. Travel-associated faecal colonization with ESBL-producing Enterobacteriaceae: incidence and risk factors. J Antimicrob Chemother. 2013;68(9):2144-53. DOI: 10.1093/jac/dkt167 PMID: 23674762

20. Kantele A, Lääveri T, Mero S, Vilkman K, Pakkanen SH, Ollgren J, et al. Antimicrobials increase travelers' risk of colonization by extended-spectrum betalactamase-producing Enterobacteriaceae. Clin Infect Dis. 2015;60(6):837-46. DOI: 1 PMID: 25613287

21. Weisenberg SA, Mediavilla JR, Chen L, Alexander EL, Rhee $\mathrm{KY}$, Kreiswirth BN, et al. Extended spectrum beta-lactamaseproducing Enterobacteriaceae in international travelers and non-travelers in New York City. PLoS ONE. 2012;7(9):e 45141. DOI: \\ PMID: 23028808

22. Angelin $M$, Forsell J, Granlund $M$, Evengård $B$, Palmgren $H$, Johansson A. Risk factors for colonization with extendedspectrum beta-lactamase producing Enterobacteriaceae in healthcare students on clinical assignment abroad: $A$ prospective study.Travel Med Infect Dis. 2015;13(3):223-9. DOI: 10.1016/j.tmaid.2015.04.007 PMID: 25982453

23. von Wintersdorff CJ, Penders J, Stobberingh EE, Oude Lashof AM, Hoebe CJ, Savelkoul PH, et al. High rates of antimicrobial drug resistance gene acquisition after international travel, The Netherlands. Emerg Infect Dis. 2014:20(4):649-57. DOI: 10.3201/eid2004.131718 PMID: 24655888

24. Paltansing S, Vlot JA, Kraakman ME, Mesman R, Bruijning ML, Bernards AT, et al. Extended-spectrum $\beta$-lactamase-producing enterobacteriaceae among travelers from the Netherlands. Emerg Infect Dis. 2013;19(8):1206-13. DOI: 10.3201/ eid1908.130257 PMID: 23885972

25. Ruppé E, Armand-Lefèvre L, Estellat C, Consigny PH, El Mniai A, Boussadia Y, et al. High Rate of Acquisition but Short Duration of Carriage of Multidrug-Resistant Enterobacteriaceae After Travel to the Tropics. Clin Infect Dis. 2015;61(4):593-600. DOI: 10.1093/cid/civ333 PMID: 25904368

26. Kuenzli E, Jaeger VK, Frei R, Neumayr A, DeCrom S, Haller S, et al. High colonization rates of extended-spectrum $\beta$-lactamase (ESBL)-producing Escherichia coli in Swiss travellers to South Asia- a prospective observational multicentre cohort study looking at epidemiology, microbiology and risk factors. BMC Infect Dis. 2014;14(1):528. DOI: 10.1186/1471-2334-14-528 PMID: 25270732

27. Lübbert C, Straube L, Stein C, Makarewicz O, Schubert S, Mössner J, et al. Colonization with extended-spectrum beta-lactamase-producing and carbapenemase-producing Enterobacteriaceae in international travelers returning to Germany. Int J Med Microbiol. 2015;305(1):148-56. DOI: \I PMID: 25547265

28. Schwaber MJ, Carmeli Y. Mortality and delay in effective therapy associated with extended-spectrum beta-lactamase production in Enterobacteriaceae bacteraemia: a systematic review and meta-analysis.J Antimicrob Chemother. 2007;60(5):913-20. DOI: 10.1093/jac/dkm318 PMID: 17848376

29. MDR-GNB Travel Working Group,Epelboin L, Robert J, TsyrinaKouyoumdjian E, Laouira S, Meyssonnier V, Caumes E. High Rate of Multidrug-Resistant Gram-Negative Bacilli Carriage and Infection in Hospitalized Returning Travelers: A Cross-Sectional Cohort Study.J Travel Med. 2015;22(5):292-9. DOI: 10.1111/ jtm.12211 PMID: 25997830

30. Kaspar T, Schweiger A, Droz S, Marschall J. Colonization with resistant microorganisms in patients transferred from abroad. who needs to be screened?Antimicrob Resist Infect Control. 2015;4(1):31. DOI: 10.1186/s13756-015-0071-6 PMID: 26213620

31. National Working Group,Lepelletier D, Andremont A, Grandbastien B. Risk of highly resistant bacteria importation from repatriates and travelers hospitalized in foreign countries: about the French recommendations to limit their spread.J Travel Med. 2011;18(5):344-51. DOI: 10.1111/j.1708 8305.2011.00547.x PMID: 21896099

32. Carattoli A. Plasmids and the spread of resistance.Int Med Microbiol. 2013;303(6-7):298-304. DOI: 10.1016/j. ijmm.2013.02.001 PMID: 23499304

33. Walsh TR, Weeks J, Livermore DM, Toleman MA. Dissemination of NDM-1 positive bacteria in the New Delhi environment and its implications for human health: an environmental point prevalence study.Lancet Infect Dis. 2011;11(5):355-62. DOI: 10.1016/S1473-3099(11)70059-7 PMID: 21478057 
34. van der Bij AK, Pitout JD. The role of international travel in the worldwide spread of multiresistant Enterobacteriaceae. Antimicrob Chemother. 2012;67(9):2090-100. DOI: II PMID: 22678728

35. Ruppé E, Armand-Lefèvre L, Estellat C, El-Mniai A, Boussadia Y, Consigny $\mathrm{PH}$, et al. Acquisition of carbapenemase-producing Enterobacteriaceae by healthy travellers to India, France, February 2012 to March 2013. Euro Surveill. 2014;19(14):20768. DOI: $10.2807 / 1560-7917 . E S 2014.19 .14 .20768$ PMID: 24739981

36. Penders J. Acquisition of ESBL- and carbapenemase producing Enterobacteriaceae during travel: The Carriage of Multiresistant Bacteria After Travel (COMBAT) Study. Maastricht: $3^{\text {rd }}$ Euregional Maastricht Symposium on Immune Compromised Traveller; 2014. Available from: http://www. minc.eu/eumict/3rd\%20EUMICT_11_Penders.pdf

37. Morrison BJ, Rubin JE. Carbapenemase producing bacteria in the food supply escaping detection.PLoS ONE. 2015;10(5):e0126717. DOI: 10.1371/journal.pone.0126717 PMID: 25966303

38. Arcilla MS, van Hattem JM, Bootsma MC, van Genderen PJ, Goorhuis A, Schultsz C, et al. The Carriage Of Multiresistant Bacteria After Travel (COMBAT) prospective cohort study: methodology and design. BMC Public Health. 2014;14(1):410. DOI: II PMID: 24775515 